IZA DP No. 9833

Uptake of Health Insurance and the Productive Safety Net Program in Rural Ethiopia

Zemzem Shigute

Anagaw D. Mebratie

Robert Sparrow
Zelalem Yilma

Getnet Alemu

Arjun S. Bedi

March 2016 


\title{
Uptake of Health Insurance and the Productive Safety Net Program in Rural Ethiopia
}

\author{
Zemzem Shigute \\ ISS, Erasmus University Rotterdam
}

\author{
Anagaw D. Mebratie \\ ISS, Erasmus University Rotterdam
}

\author{
Robert Sparrow \\ Australian National University \\ and IZA
}

\author{
Zelalem Yilma \\ ISS, Erasmus University Rotterdam
}

\author{
Getnet Alemu \\ Addis Ababa University
}

Arjun S. Bedi

ISS, Erasmus University Rotterdam and IZA

\section{Discussion Paper No. 9833 \\ March 2016}

\author{
IZA \\ P.O. Box 7240 \\ 53072 Bonn \\ Germany \\ Phone: +49-228-3894-0 \\ Fax: +49-228-3894-180 \\ E-mail: iza@iza.org
}

Any opinions expressed here are those of the author(s) and not those of IZA. Research published in this series may include views on policy, but the institute itself takes no institutional policy positions. The IZA research network is committed to the IZA Guiding Principles of Research Integrity.

The Institute for the Study of Labor (IZA) in Bonn is a local and virtual international research center and a place of communication between science, politics and business. IZA is an independent nonprofit organization supported by Deutsche Post Foundation. The center is associated with the University of Bonn and offers a stimulating research environment through its international network, workshops and conferences, data service, project support, research visits and doctoral program. IZA engages in (i) original and internationally competitive research in all fields of labor economics, (ii) development of policy concepts, and (iii) dissemination of research results and concepts to the interested public.

IZA Discussion Papers often represent preliminary work and are circulated to encourage discussion. Citation of such a paper should account for its provisional character. A revised version may be available directly from the author. 


\section{ABSTRACT \\ Uptake of Health Insurance and the Productive Safety Net Program in Rural Ethiopia}

Due to lack of well-developed insurance, credit and labor markets, rural families in Ethiopia are exposed to a range of covariate and idiosyncratic risks. In 2005 , to deal with the consequences of covariate risks, the government implemented the Productive Safety Net Program (PSNP) - an active labor market program to build rural assets, and in 2011, to mitigate the financial consequences of ill-health, the government introduced a pilot Community Based Health Insurance (CBHI) Scheme. This paper explores whether scheme uptake and retention is affected by access to the PSNP. Based on several rounds of household level panel data and qualitative information, the analysis shows that participating in the PSNP increases the probability of $\mathrm{CBHI}$ uptake by 24 percentage points and enhances scheme retention by 10 percentage points. Analysis of the channels through which the PSNP influences $\mathrm{CBH}$ uptake indicates that the bulk of the effect may be attributed to explicit and implicit pressure applied by government officials on PSNP beneficiaries. Whether this is a desirable approach is debatable. Nevertheless, the results suggest that membership in existing social protection programs may be leveraged to spread new schemes and potentially accelerate poverty reduction efforts.

JEL Classification: J65, J48, I13

Keywords: productive safety net program, active labor market program, Ethiopia, community based health insurance, uptake of health insurance

Corresponding author:

Arjun S. Bedi

International Institute of Social Studies (ISS)

Erasmus University Rotterdam

Kortenaerkade 12

2518 AX Den Haag

The Netherlands

E-mail: bedi@iss.nl 


\section{Introduction}

Rural households in Ethiopia face substantial covariate and idiosyncratic risks. As in the case of other developing countries, dependence on volatile rain-fed agriculture and absence of well-developed markets for insurance and credit exacerbate the effects of these risks. At the same time, exposure to multiple-risks increases vulnerability (Dercon 2002, Rosenzweig 2001, Wagstaff 2007). For instance, when faced with illnesses, poor households may not be able to afford health care which may impair their health status. Borrowing or selling assets to meet health care expenses may lead to impoverishment which further weakens their ability to withstand non-health related shocks. The potential interplay between different types of shocks suggests that multiple interventions may simultaneously be needed to provide effective social protection for vulnerable groups (Ranson 2002, Ssewamala et al. 2010, Wagstaff 2007). Although there is no dearth of studies which analyse access to and the impact of different types of interventions, research which focuses on potential links between different social protection programs is scarce.

In recent years, a number of developing countries have introduced voluntary community based health insurance schemes to mitigate the potentially impoverishing effects of ill-health. A common problem plaguing such voluntary health insurance schemes is low enrolment and high dropout rates (for a review see Mebratie et al. 2013) and in an attempt to increase demand for insurance, bundling of health insurance with microfinance loans has been suggested as a potential strategy (Banerjee et al. 2014, Dror et al. 2009, Hamid et al. 2011, Ranson 2002, Ranson et al. 2006). Evidence on the effectiveness of such an approach yields a mixed picture. For instance, Banerjee et al. (2014) used data from 201 villages in India of which 101 were offered a product which combined microfinance and health insurance while 100 villages served as controls, to analyse the effectiveness of offering health 
insurance through a microfinance scheme. They concluded that this experiment was unsuccessful as the poor quality of the insurance product led to negative effects which culminated in a withdrawal from the microfinance scheme itself. On a more positive note, Hamid et al. (2011) found that microcredit clients of the Grameen Bank in Bangladesh who had access to health insurance offered by Grameen Bank were more likely to be food sufficient as compared to microcredit clients who did not have access to the insurance product. Based on their study of providing health insurance through the Self-Employed Women's Association (SEWA) in India, Ranson et al. (2006) argue that offering health insurance through community-based associations like SEWA is more effective in terms of reaching out to low-income women as compared to stand-alone schemes. The authors also argue that offering insurance through existing programs offsets the lack of institutional capacity to run such schemes.

A similar enrolment issue that has been observed in developing countries that have attempted to reach Universal Health Coverage (UHC) through social insurance based programs is the so-called missing-middle problem. The formal sector can be obliged to enrol through typical social insurance designs, with compulsory payroll based contributions. However, such mechanisms are not effective for achieving universal coverage in countries with a large informal economy and labour market. The missing-middle problem describes the phenomenon where mandatory enrolment of formal sector workers is combined with subsidized premiums targeted to the poorest, while insurance uptake for the remainder of the informal sector relies to some extent on voluntary enrolment. International experiences suggest that it is extremely difficult to convince informal sector households to enrol voluntarily into health insurance, without providing strong (monetary) incentives to do so (Capuno et al. 2014 and Wagstaff et al. 2014). However, there is no empirical evidence on 
the effectiveness of policy instruments that leverage insurance uptake for the informal sector by integrating social policies.

In June 2011, the Ethiopian government introduced a voluntary Community Based Health Insurance in thirteen rural districts of the country. Several of these districts are food insecure and are also locations where the Productive Safety Net Program (PSNP), the government's flagship program to deal with covariate risk, also operates. The PSNP program targets food insecure households in chronically food insecure regions. Recognizing the interlinkages between the impoverishing effects of different shocks, an explicit goal is to use the PSNP as a platform to help food insecure households access other social protection programs (MoARD 2010). Such an approach is potentially promising in terms of helping the most vulnerable households deal with multiple shocks and at the same time increasing demand for insurance.

Whether the PSNP does enhance access to other social protection programs for food insecure households and more importantly, the channels through which this takes place are open questions. A priori it may be expected that food insecure households will be less likely to afford insurance. However, there are a number of reasons why PSNP beneficiaries may be more likely to join the scheme such as a higher chance of obtaining a premium payment waiver or greater information about the benefits of insurance scheme as compared to non-PSNP members. To shed light on such issues, this paper examines the links between the CBHI scheme and the PSNP. In particular, we examine whether being a PSNP beneficiary influences initial enrolment in the CBHI scheme and thereafter whether it influences scheme retention. While the effect of various factors on enrolment and drop-out has been explored by Mebratie et al. (2015a) and Mebratie et al. (2015b), the focus of these papers was not on the role played by the PSNP. The paper's main contribution is that we 
attempt to identify the channels through which the PSNP may influence uptake and renewal. The study relies on several rounds of focus group discussions and key informant interviews, three rounds of panel data and a health facility survey. It should be noted that the possibility of using existing social protection programs to encourage entry into a new program is of interest not only to Ethiopia but also to other countries that are using voluntary health insurance schemes to encourage access to health care.

The next section of the paper briefly describes certain features of the PSNP and CBHI schemes. Section 3 discusses the data, section 4 lays out the research methods, section 5 contains empirical results and section 6 concludes.

\section{A brief overview of PSNP and CBHI in Ethiopia}

The Productive Safety Net Program (PSNP) has been designed to deal with covariate risk while the recently piloted Community-Based Health Insurance (CBHI) is expected to become the key program to deal with the financial consequences of ill-health.

\subsection{The Productive Safety Net Program (PSNP)}

In 2003, the Ethiopian government initiated discussions with its development partners to replace the existing emergency response of using food aid to fill consumption gaps. These consultations led to the creation of the Productive Safety Net Program which articulated a shift from an emergency relief system to sustainable food security. The scheme was launched in January 2005.

The PSNP has three main objectives. These are to protect food insecure households in food insecure regions by providing resources to smooth consumption during the lean season, protect households by preventing sales of household assets and reduce the probability of borrowing and further impoverishment and finally to promote livelihoods by 
building community assets with development potential. ${ }^{1}$ Program participants are selected through a participatory approach, and households with able-bodied members are expected to undertake public works activities in return for payment either in cash or in kind. The program operates in 319 food insecure districts (40\% of the total districts) located in eight regions of the country (MoARD 2011, FDRE 2012). In 2013-14 the program had a cash budget of about $\$ 205$ million and access to food resources to the tune of 274,844 metric tonnes and provided social transfers to about 6 million food insecure individuals either through "public works" activities (4.8 million) or as "direct support" (1.2 million) for labor constrained households (MoA 2013).

A key objective of the current phase of the PSNP is to enhance achievement of the program's objectives by forging links between the PSNP and other food security and development programs. As stated in the Program Implementation Manual, PIM (MoARD 2010: 6):

"The PSNP is not a project but a key element of local development planning. PSNP plans are integrated into wider development plans at woreda, zone, region and federal levels."

\subsection{Community Based Health Insurance (CBHI)}

In June 2011, the Ethiopian CBHI pilot was launched in 13 districts (for a detailed description, see Mebratie et al., 2015a). The scheme is government-driven but with community engagement in insurance design, participation, management and supervision. At the design phase of the scheme, regional governments were involved in determining benefit packages, registration fees, premium payments and co-payments. The role-out phase

\footnotetext{
${ }^{1}$ A district is classified as food insecure on the basis of the frequency of requiring food assistance in the ten years preceding 2004. Food insecure households within such districts are households who fail to produce enough to meet their consumption needs even when there is normal rainfall (MoARD, 2010:8).
} 
involved a two-step process, with first the community deciding (based on a general assembly majority vote) whether to participate in the scheme and subsequently households could choose whether to enrol or not. The insurance covers households rather than just individuals, in order to reduce adverse selection.

The scheme covers inpatient and outpatient health care services at public facilities. Care at private facilities is not covered unless drugs or services are not available at public facilities. Transportations costs, medical treatment with largely cosmetic value and treatment outside Ethiopia are not covered. If members adhere to the scheme's referral procedure, they are exempt from copayments.

Monthly premiums lie in the range of 0.4-0.6 percent of household monthly income. To stimulate enrolment, fee waivers are targeted to the poorest 10 percent of the population. Identification of the poorest households is based on interactions between local government officials and the community. Of particular interest for this paper is that 9 of the 12 districts are classified as food insecure and both the PSNP and the CBHI operate in these districts.

\section{Data}

This empirical analysis is based on household panel data, with survey rounds in 2011, 2012 and 2013. In addition, a health facility survey was conducted in 2011 and qualitative information was gathered through Key Informant Interviews (KII) and Focus Group Discussions (FGD).

Data collection followed a stratified sampling design and covered 12 of the districts that had been identified by the government for participation in the CBHI pilot. From each district, six villages were randomly selected and from each village we randomly selected 17 households for a combined sample of 1,224 households. The follow-up surveys in 2012 and 
2013 revisited 1,203 and 1,186 households respectively. The questionnaire included modules on individual and household socio-economic characteristics and demographics, assets, employment, consumption expenditure, health and health care, access to credit, social networks, and shocks. Crucial for this analysis is that the questionnaire asked whether the household is a member of the PSNP, and the 2012 and 2013 questionnaires included questions on participation in the CBHI pilot scheme. The 2011 health facility survey visited 3 randomly chosen health centers in each district, collecting information on quality of medical care and access to health facilities.

The qualitative information was collected in three rounds. The first round of FGDs and KIIs were conducted in 2012 in four districts (one in each of the regions) where the pilot CBHI had been launched. The second, a more focused data collection effort took place in 2014 in a district where both the CBHI and the PSNP were active (a district in Oromia region). FGDs were conducted in four villages. In each of the villages the FGDs included up to eight household heads or their representatives. While all the FGD participants were PSNP members, all were not members of the CBHI scheme. The discussions focused on the interactions between the PSNP and CBHI schemes. The second round of KII was held with officials responsible for executing the PSNP and the CBHI. This was held at district and village levels. ${ }^{2}$ The key informants were also asked to provide inputs on the interaction between the PSNP and the CBHI and whether and how the PSNP was used as a platform to promote and encourage uptake of the $\mathrm{CBHI}$ scheme. A final round of six FGDs was conducted in Tigray and in SNNPR regions in June 2015. The discussions focused not just

\footnotetext{
2 At the woreda level, discussions were held with officials in the woreda agricultural office who are directly responsible for executing the PSNP and indirectly involved in CBHI implementation. The officials interviewed at the kebele level are responsible for implementing both programs.
} 
on the interaction between PSNP and CBHI but also on the functioning of the $\mathrm{CBHI}$ in general.

\section{Analytical Framework}

The empirical analysis focuses on identifying the effect of being a PSNP beneficiary on enrolment and conditional on enrolment, on retention. Drawing on the focus group discussions, the key informant interviews and the existing literature, we treat the decision to join the scheme or to renew as a function of two broad sets of variables - these are a range of variables that capture scheme affordability and variables which captures the extent to which a household may be expected to gain from insurance. The latter is further treated as a function of household traits (health status, demographic composition), household understanding and knowledge of insurance and supply side variables which capture accessibility to care and quality of care.

To elaborate, scheme affordability is assumed to depend on a household's socioeconomic characteristics (SEC). These characteristics include a household's consumption quintile, the household head's educational level, access to credit $(A C)$ as indicated by membership in traditional or modern credit associations, savings and whether a household has availed of loans and finally, the key variable of interest, that is, whether households are affiliated to the productive safety net programme (PSNP).

Expected gains from the scheme are treated as a function of the chance of using medical care and the specification includes variables that capture illness episodes and selfassessed household health status (HS). A set of demographic traits (DT) is also included. We capture understanding of health insurance $(U H I)$ on the basis of responses to four questions

- these are, only the sick purchase insurance, CBHI is a saving scheme, CBHI pays for 
health care, the $\mathrm{CBHI}$ premium will be returned if medical care is not used. To capture scheme knowledge $(S K)$ we include a variable which indicates whether household members attended community-level meetings before scheme launch, whether any household member works in a government position or is involved in managing the CBHI scheme. In the case of the renewal decision we include scheme experience ( $S E$ ) which is determined on the basis of responses to five questions which enquire about the functioning of the scheme. To the extent that the expected returns from the scheme depend on supply-side (SS) variables, the specification includes time taken to reach the closest health centre and public hospital and a range of variables that captures the quality of health care. This includes waiting time to see a health care provider, availability of various types of medical equipment, and respondent's perceptions of the quality of health care.

Combining all these factors leads to specification (1), where the probability that household $(b)$ enrols in the scheme or renews enrolment $(Y)$ in time $t$ depends on variables in previous time periods. That is,

$$
p\left(Y_{b t}\right)=f\left(\begin{array}{l}
\alpha S E C_{b t-1}, \phi P S N P_{b t-1}, \tau A C_{b t-1}, \beta H S_{b t-1}, \theta D T_{b t-1}, \\
\pi U H I_{b t-1}, v S K_{b t-1}, \omega S E_{b t-1}, \delta S S_{b t-2}, \mu_{b t}
\end{array}\right)
$$

Several variants of specification (1) are estimated using logit specifications for enrolment and retention while the duration of enrolment is estimated using an ordered logit specification (not enrolled, enrolled for one year, enrolled for two years). Note that we regress enrolment and retention in 2013 as a function of covariates in 2012, except for the quality of medical services variables for which we have data only for 2011. These lagged specifications are unlikely to be affected by endogeneity of some of the independent variables. In addition, we estimate specifications which rely on PSNP status in 2011 as well 
as linear probability models of current CBHI status on current PSNP status controlling for household fixed effects. ${ }^{3}$

Estimates of (1) are used to provide an assessment of the extent to which participation in the PSNP is associated with insurance uptake/retention. Thereafter, we use both the qualitative information and responses to survey-based questions on the reasons for enrolling in (dropping-out from) the scheme to try and pin down the channels through which the PSNP influences uptake.

\section{Results}

\subsection{PSNP and CBHI Uptake}

As shown in Table 1, in April 2012, scheme enrolment reached 41 percent. About 18 percent of those who had enrolled in 2012 dropped out in 2013 but new entrants more than made up for the dropout, translating into an overall enrolment rate of 48 percent in April 2013. With regard to the PSNP, about 17 to 20 percent of the sample households are PSNP beneficiaries (Table 2) and PSNP beneficiaries are far more likely to participate in the CBHI scheme as compared to those who are not beneficiaries. For instance, in 2012 about 60 percent of PSNP beneficiaries enrolled in the scheme as compared to an enrolment rate of 36 percent amongst non-beneficiaries while in 2013 the corresponding figures were 68 and 44 percent.

Table 3 provides estimates based on a series of specifications where the aim is to identify the effect of participation in the PSNP on enrolment and retention. We start with a very parsimonious regression (only PSNP) and then add sets of covariates to examine the

\footnotetext{
${ }^{3}$ The results are not sensitive to these changes and continue to display large effects of PSNP on CBHI status.
} 
sensitivity of the PSNP effect. ${ }^{4}$ The striking aspect of the estimates is that regardless of the specification, PSNP participation in 2012 has a large and statistically significant effect on the probability that a household enrols in the scheme in 2013. The effect of PSNP on enrolment without including any covariates is about 22 percentage points and after controlling for the full-range of attributes we find that being a member of the PSNP scheme is associated with a 24 percentage point increase in the probability of being enrolled in the $\mathrm{CBHI}$ scheme. The stability of the effects suggests that there is a large and positive effect of PSNP on enrolment which is not mediated through any other channels. Ordered logit estimates based on the most complete specification show that the PSNP is associated with a 27 percentage point increase in the probability that a household remains enrolled for two years. As may be inferred from these two sets of enrolment estimates, participation in the PSNP influences enrolment and reduces scheme dropout or vice versa enhances retention. The most complete specification indicates that participation in the PSNP scheme enhances the probability of retention by 10 percentage points.

\subsection{Why does PSNP membership enhance CBHI uptake?}

The PSNP is meant to target food-insecure households in food-insecure districts and it may be expected that such households will find it difficult to buy insurance and hence will be less likely to access the $\mathrm{CBHI}$ scheme. However, the estimates display that participation in the PSNP is positively linked to enrolment and retention. This is an intriguing pattern and there could be several channels through which participation in the PSNP may translate into higher CBHI uptake. The following sections pursue various potential explanations.

First, it is possible that PSNP members have certain traits that makes insurance more attractive for them. For instance, the PSNP is meant for food-insecure households and it

\footnotetext{
${ }^{4}$ Detailed estimates are available on request
} 
may be that PSNP members are less healthy and more likely to use health care which in turn increases their desire to acquire insurance. Second, PSNP membership may enable access to fee-waivers which in turn enhances uptake and retention. Third, although we control for scheme understanding and knowledge of insurance, it is possible that PSNP members have greater scheme knowledge and greater understanding of the scheme which in turn translates into greater uptake. Fourth, it is possible that administrators explicitly or implicitly coerce households to join the CBHI scheme and since households with access to the PSNP depend on administrators to provide scheme payments they are more susceptible to pressure. While we have information on whether explicit pressure was applied it is certainly more difficult to discover the manner in which, if at all, implicit pressure is applied. In any case, we explore the veracity of each of these explanations using both the qualitative and the quantitative information at our disposal.

\subsubsection{Who accesses the PSNP?}

To explore differences in socio-economic status and other variables which may have a bearing on scheme uptake we provide descriptive statistics conditional on PSNP membership (Table 4) and also estimate a logit model to identify factors associated with the probability of participating in the PSNP (Table 5). Consistent with the targeting mechanism of the PSNP the descriptive statistics show that households falling in the poorest consumption quintile are far more likely to be PSNP members - 31\% of PSNP members are in the lowest consumption quintile as compared to $18 \%$ of non-members. PSNP household heads are also more likely to be uneducated (50 versus $41 \%$ ) and more likely to have taken out loans (39 versus 29\%). In terms of health status, the picture is a little muddled as it shows that PSNP members are more likely to report that they are in good health, while at the same time they are more likely to be experiencing chronic illnesses (29 versus $16 \%$ ). 
The regression estimates presented in Table 5 underline the point that households in the poorest quintile are more likely to be enrolled in the PSNP. After controlling for covariates, there is no link between educational status and PSNP participation. Chronic illness, at least in 2013, and PSNP participation are positively correlated. Similarly, households with outstanding loans are more likely to join the PSNP. While having an outstanding loan indicates that a household has access to credit it may also be interpreted in terms of a marker of poverty and an inability to finance needs without borrowing. Regardless of the interpretation of the correlations between chronic illnesses and PSNP participation and between the presence of outstanding loans and PSNP participation, the estimates in Table 3 show that the inclusion of these two variables does not particularly dampen the PSNP effect (see rows 5 and 7). The denouement is that there is no strong evidence to support the claim that PSNP participants have observed traits that make them more susceptible to joining the CBHI scheme.

\subsubsection{Fee-waivers, knowledge of insurance and scheme understanding}

According to scheme guidelines, the poorest 10 percent of households are eligible for a feewaiver. Prima facie and on the basis of the information provided in the previous section, it may be expected that PSNP members are more likely to belong to this category of households. Our data show that in both survey rounds only about 3 percent of households join the scheme with a fee waiver. While this is rather low as compared to the target, of greater interest is that despite their poorer socio-economic status there is no evidence that PSNP members are more likely to receive a fee-waiver. As shown in Table 6, the proportion of PSNP and non-PSNP members with a fee-waiver is the same.

Our data include a series of questions which test understanding of health insurance in general and scheme-specific knowledge. It is likely that households with a greater 
understanding of health insurance and more information about the working of the $\mathrm{CBHI}$ scheme are more likely to enrol. At the same time it is possible that due to their enrolment in an existing scheme, PSNP members are more willing to attend the awareness-generating activities which preceded the launch of the CBHI. Table 6 contains information on differences in understanding of health insurance and scheme knowledge conditional on PSNP membership. We find some evidence that PSNP participants have a slightly better understanding of the concept of health insurance, as we find statistically significant differences for one of the four questions that probe health insurance literacy (i.e. whether or not $\mathrm{CBHI}$ is meant only for sick people).

In terms of knowledge and participation in the CBHI scheme, PSNP participants are more likely to have attended meetings before the launch of the CBHI and are also more likely to be involved in CBHI management - about 16 percent of PSNP members participate in CBHI management while it is 7 percent for non-members (Table 6). This is consistent with the government's plan to use the PSNP as a platform to create awareness and deliver other development and social protection programs which as a consequence translates into higher participation of PSNP members in the management of community level positions like CBHI management. Given the relationship between PSNP membership and scheme involvement it is possible that a part of the PSNP effect may be attributed to differences in involvement in scheme management. This does seem to be the case when we compare the estimates in rows 5 and 6 of Table 3. The inclusion of the knowledge and participation variables leads to a 3 percentage point reduction in the effect of PSNP. However, the PSNP effect remains large and as shown in rows 8 and 9 of Table 3 and in the detailed estimates (not reported here), there are independent and large effects of PSNP affiliation and of involvement in $\mathrm{CBHI}$ management on uptake and retention. 


\subsubsection{Pressure to join the scheme}

Scheme membership is supposed to be voluntary. However, survey-based responses on the main reason for joining the scheme as well as information gathered from the qualitative work suggests that enrolment may not be entirely voluntary. About 10 percent of those who have joined the scheme indicate that they were pressured to enrol by village level government officials. As shown in Table 6, this proportion is substantially higher $(15 \%)$ among PSNP participants as opposed to non-participants (8\%). The susceptibility of PSNP members to pressure was also revealed in some of the focus group discussions where respondents pointed out that the $\mathrm{CBHI}$ premiums are at times deducted from their PSNP payments. For instance an uninsured FGD participant in Oromia region said,

"A kebele official reduced my monthly transfer payment from PSNP and informed me that the reduced money was for CBHI membership contribution. I said I did not want to enrol in the scheme and asked him to give me my full PSNP benefit. However, he did not pay me. So, I accused him to a higher kebele official and I got my money back" [Discussed on December 23, 2012].

Similarly, an insured FGD participant from Oromia district reported that,

"In 2012, one woreda cabinet member came and collected the full CBHI premium by deducting it from the PSNP transfer. I went home with reduced transfer payment and I suffered as I didn't plan on it. All the cabinet cares about is fulfilling their quota. Not how valuable the money is to our family" [Discussed on September 8, 2014].

Such views are not restricted to Oromia district and FGDs in other parts of the country

also revealed several instances where officials deducted the $\mathrm{CBHI}$ premium contribution from the monthly PSNP benefit without obtaining the consent of beneficiaries.

To examine the role of pressure in driving the PSNP effect we estimated specifications excluding households who responded that they had been forced to enrol in the scheme. Dropping such observations did not have a substantial effect on the magnitude of the PSNP 
effect suggesting that the link between PSNP membership and reported (explicit) pressure is not the main reason behind the PSNP effect.

While explicit pressure may not be the main factor for the large PSNP effect, the responses from the key informant interviews suggests that strong persuasion may often be used. As implied by the response of the FGD respondent provided above, one of the performance yardsticks of village level government officials is enrolment in the CBHI which is likely to lead to overzealous behaviour. Regardless of whether officials were willing to admit the use of pressure, officials provided two core arguments for their actions. First, they argued that PSNP members are particularly vulnerable, unable to afford health care and find it harder to borrow to finance health care and since the CBHI scheme offers them access to health care at a very affordable price they need to be encouraged to join. ${ }^{5}$ For instance an official in Oromia region argued,

"We have to force PSNP members to join CBHI because we know they will benefit. Getting resources through borrowing is not usually the case for PSNP beneficiaries as they lack collateral which is needed by lenders in most cases" [Interviewed on September 10, 2014].

There is a second and perhaps more insightful reason for the pressure exerted by officials. The same local government officials are responsible for implementing the CBHI and the PSNP. While the performance target for the CBHI is based on uptake the target for the PSNP requires the construction of public works. In order to meet these construction targets the officials need to rely on the labour contribution of PSNP beneficiaries which in turn raises their interest in the health and work capacity of PSNP beneficiaries. For instance during an interview a village level official remarked,

\footnotetext{
5 The various measures used to determine scheme affordability indicate that the scheme is equally affordable for both PSNP and non-PSNP members and for a majority of households - about 70 percent. However, PSNP beneficiaries are more likely to be in debt they are less likely to have savings accounts and be members of credit and savings associations (see Tables 4 and 6).
} 
"We inform PSNP members to join the scheme because we want them to get immediate treatment when they get sick. If they are not treated immediately, it affects their performance in public works. These beneficiaries do development work and we don't want them to fall sick so the idea is if they buy insurance and get care then it may also improve their health outcomes" [Interviewed on October 31, 2014].

Officials clearly have a keen sense of the links between the two schemes and their desire to meet the objectives of both the programs creates an incentive for them to push respondents to join the schemes.

While officials have used pressure and justify their use of pressure, some respondents were also aware of the benefits of both schemes while others highlighted their changing attitudes towards the actions taken by officials. For instance, an FGD participant in Oromia mentioned,

"I can feed my family with the payment I get from PSNP PW and my kids can go to school not worrying about whether and what they will eat. Because of my CBHI, I and my kids can get proper treatment whenever we get sick. If it wasn't for CBHI I might have to go around my neighbourhood and ask for borrowing which is very difficult" [Discussed on September 9, 2014].

During an FGD, a participant in Tigray region pointed out,

"At the beginning of the scheme, we were not convinced of the benefit of CBHI and we resisted joining the scheme. I remember the first membership was deducted from the payment of PSNP and everybody was opposed to what the leaders did. But now we are the ones nagging them to renew our membership" [Discussed on June 9, 2015].

\section{Concluding remarks}

Inspired by the low uptake of community based health insurance (CBHI) in a number of schemes operating in developing nations and the plans of the Ethiopian government to use its flagship social protection initiative, the productive safety net programme (PSNP) as a platform to help households access other social protection interventions, this paper examined the link between participation in the PSNP and uptake of a recently introduced CBHI scheme. Whether it is possible to use participation in existing social protection 
programs to leverage uptake of new programs is a question of wider interest and not confined to Ethiopia.

The paper was based on three rounds of panel data, a health facility survey and information gathered from key informant interviews and focus group discussions. We found a strong link between participation in the PSNP and uptake of and retention in the CBHI scheme. Despite controlling for a large number of covariates which may influence both PSNP and CBHI participation we found that participation in the CBHI was associated with a 24 percentage point increase in the probability of taking out insurance and a 10 percentage point increase in the probability of renewing insurance. These large effects are intriguing, especially since the PSNP caters to food insecure households in food insecure districts.

We considered a variety of explanations which may be responsible for the higher participation rates of PSNP beneficiaries. We discovered that a higher proportion of PSNP beneficiaries had chronic illnesses ( 29 vs. 16 percent), they had attended more CBHI-related awareness meetings and were more likely to be involved in CBHI management (16 vs. 7 percent). However, controlling for these variables did not substantially alter the magnitude of the PSNP effect suggesting that PSNP participation has a direct effect on CBHI uptake which is not mediated through variables which maybe correlated with PSNP status. Surveybased responses to questions on why households joined the CBHI revealed that about 15 percent of PSNP beneficiaries joined the scheme due to pressure exerted by government officials while the corresponding figure was 8 percent in the case of non-beneficiaries. The FGD and KII confirmed the use of pressure, especially on PSNP beneficiaries. Since there are limited differences in observable traits between PSNP and non-PSNP members it is likely that the PSNP effect is mainly driven by the use of explicit and implicit pressure on PSNP beneficiaries. 
There were two main reasons offered by officials for strongly advising PSNP beneficiaries to buy insurance. First, some program officials argued that due to the inability to finance health care and the relatively lower socio-economic status of PSNP beneficiaries, they should take advantage of the affordable insurance as it is to their benefit, even if they are not aware of it. Second, at the village level the same government officials are responsible for implementing both the PSNP and the CBHI and this provides an incentive for officials to push both schemes as $\mathrm{CBHI}$ uptake enhances access to health care and might reduce illness-related losses in labour contributions which are needed to build rural infrastructure through the PSNP.

The use of pressure by the administration is contrary to the design of the CBHI scheme. Nevertheless, what we are able to show in this paper is that the approach of using participation in an existing social protection can be successfully used to leverage insurance uptake amongst perhaps the most economically vulnerable groups in rural Ethiopia. Whether this can be sustained and whether it is justified, as argued by officials is debatable. However, if one of the goals is to universalize access to health care in Ethiopia and other countries in the region, then exploring how roll out of health insurance may be integrated with other social protection programs is a policy option that is worth considering. 


\section{References}

Banerjee, A., E. Duflo and R. Hornbeck (2014) 'Bundling Health Insurance and Microfinance in India: There Cannot be Adverse Selection if there is no Demand', American Economic Review 104(5): 291-297

Capuno, J.J., A.D. Kraft, S. Quimbo, C.R. Tan and A. Wagstaff (2014) 'Effects of Interventions to Raise Voluntary Enrollment in a Social Health Insurance Scheme: A Cluster Randomized Trial', World Bank Policy Research Working Paper 6893.

Criel, B. and M.P. Waelkens (2003) 'Declining Subscriptions to the Maliando Mutual Health Organisation in Guinea-Conakry (West Africa): What is Going Wrong?', Social Science \& Medicine 57(7): 1205-1219.

Dercon, S. (2002) 'Income Risk, Coping Strategies, and Safety Nets', World Bank Research Observer 17(2):141-166.

Dong, H., M. De Allegri, D. Gnawali, A. Souares and R. Sauerborn (2009) 'Drop-Out Analysis of Community-Based Health Insurance Membership at Nouna, Burkina Faso', Health Policy 92(2): 174-179.

Dror, D.M., R. Radermacher, S.B. Khadilkar, P. Schout, F. Hay, A. Singh, \& R. Koren (2009) 'Microinsurance: Innovations In Low-Cost Health Insurance', Health Affairs 28 (6):1788.

Federal Democratic Republic of Ethiopia Population Census Commission (2012) 'Summary and Statistical Report of the 2012 Projected Population Size by Age and Sex based on the 2012 Population and Housing based on the Census', Addis Ababa, July 2012

Gilligan, D.O., J. Hoddinott and A.S. Taffesse (2009) 'The Impact of Ethiopia's Productive Safety Net Program and its Linkages', The Journal of Development Studies 45(10): 16841706.

Hamid, S.A., J. Roberts and P. Mosley (2011) 'Can Micro Health Insurance Reduce Poverty? Evidence from Bangladesh', Journal of Risk and Insurance 78 (1): 57-82.

Mebratie, A.D., R. Sparrow, Z. Yilma, G. Alemu and A.S. Bedi (2015a) 'Enrollment in Ethiopia's Community-Based Health Insurance Scheme', World Development 74: 58-76.

Mebratie, A.D., R. Sparrow, Z. Yilma, G. Alemu and A.S. Bedi (2015b) 'Dropping Out of Ethiopia's Community-Based Health Insurance Scheme', forthcoming in Health Policy and Planning. doi: 10.1093/heapol/czu142.

Mebratie, A., R. Sparrow, G. Alemu and A.S. Bedi (2013) 'Community-Based Health Insurance Schemes', ISS Working Paper Series/General Series 568. 
Mladovsky, P. (2014) 'Why do People Drop Out of Community-Based Health Insurance? Findings from an Exploratory Household Survey in Senegal', Social Science \& Medicine 107: 78-88.

MoA (2013) ‘2006 EFY PSNP Public Works Annual Plan’ Addis Ababa, Ethiopia, Ministry of Agriculture.

MoARD (2011) 'Productive Safety Net and Household Asset Building Programs, Annual Work Plan and Budget for 2011/12 (2004EFY) '. Addis Ababa, Ethiopia: Ministry of Agriculture, Disaster Risk Management and Food Security Sector Food Security Coordination Directorate.

MoARD (2010) 'Productive Safety Net Program, Program Implementation Manual'. Addis Ababa, Ethiopia: Ministry of Agriculture and Rural Development, Federal Government of Ethiopia.

Ranson, M.K., T. Sinha, M. Chatterjee, A. Acharya, A. Bhavsar, S.S. Morris \& A.J. Mills (2006) 'Making health insurance work for the poor: learning from the Self-Employed Women's Association's (SEWA) community-based health insurance scheme in India", Social Science \& Medicine 62 (3): 707-720.

Ranson, M.K. (2002) 'Reduction of catastrophic health care expenditures by a communitybased health insurance scheme in Gujarat, India: current experiences and challenges', Bulletin of the World Health Organization 80 (8): 613-621.

Rosenzweig, M.R. (2001) 'Savings Behaviour in Low-Income Countries', Oxford Review of Economic Policy 17(1): 40-54.

Ssewamala, F.M., E. Sperber, J.M. Zimmerman and L. Karimli (2010) 'The Potential of asset-based Development Strategies for Poverty Alleviation in Sub-Saharan Africa', International Journal of Social Welfare 19(4): 433-443.

Wagstaff, A. 2007, 'The Economic Consequences of Health Shocks: Evidence from Vietnam', Journal of Health Economics 26 (1): 82-100.

Wagstaff, A., H.T.H. Nguyen, H. Dao and S. Bales (2014) 'Encouraging health insurance for the informal sector: A cluster randomized trial', World Bank Policy Research Working Paper 6910. 
Table 1

Enrolment and drop-out - CBHI Ethiopia

\begin{tabular}{lcc|cccccc}
\hline \multirow{2}{*}{ Region } & \multicolumn{2}{c|}{ April 2012 } & \multicolumn{6}{c}{ April 2013 } \\
\cline { 2 - 9 } & \multicolumn{2}{c}{ Enrolment } & \multicolumn{2}{c}{ Enrolment } & Drop-outs & \multicolumn{2}{c}{$\begin{array}{c}\text { New } \\
\text { enrolees }\end{array}$} \\
\cline { 2 - 9 } & $\mathbf{0}$ & $\mathbf{N}$ & $\mathbf{0}$ & $\mathbf{N}$ & $\mathbf{0}$ & $\mathbf{N}$ & $\mathbf{\%}$ & $\mathbf{N}$ \\
\hline Tigray & 33.9 & 101 & 50.2 & 146 & 26.5 & 26 & 38.3 & 74 \\
Amhara & 49.5 & 148 & 62.7 & 188 & 6.9 & 10 & 33.8 & 52 \\
Oromia & 44.2 & 133 & 44.5 & 133 & 21.2 & 28 & 17.4 & 29 \\
SNNPR & 35.3 & 107 & 35.4 & 107 & 21.5 & 23 & 11.8 & 23 \\
& & & & & & & & \\
Total & $\mathbf{4 0 . 7}$ & $\mathbf{4 8 9}$ & $\mathbf{4 8 . 2}$ & $\mathbf{5 7 4}$ & $\mathbf{1 8 . 0}$ & $\mathbf{8 7}$ & $\mathbf{2 5 . 1}$ & $\mathbf{1 7 8}$ \\
\hline
\end{tabular}

Table 2

CBHI uptake and PSNP membership

\begin{tabular}{lcccccc}
\hline Enrolled & \multicolumn{3}{c}{ April 2012 } & \multicolumn{3}{c}{ April 2013 } \\
\cline { 2 - 7 } in the \\
\cline { 2 - 6 } & $\begin{array}{c}\text { PSNP } \\
\text { member }\end{array}$ & $\begin{array}{c}\text { Non- } \\
\text { members }\end{array}$ & Total & $\begin{array}{c}\text { PSNP } \\
\text { member }\end{array}$ & $\begin{array}{c}\text { Non- } \\
\text { member }\end{array}$ & Total \\
\hline Enrolled & 141 & 345 & 486 & 136 & 438 & 574 \\
& $(60.3)$ & $(35.9)$ & $(41)$ & $(67.7)$ & $(44.2)$ & $(48)$ \\
Total & 234 & 962 & 1196 & 201 & 990 & 1191 \\
\hline
\end{tabular}


Table 3

Probability of CBHI enrolment and renewal - marginal effects of PSNP after (ordered) logit (std. error)

\begin{tabular}{|c|c|c|c|c|}
\hline \multirow[t]{2}{*}{ VARIABLES } & \multirow{2}{*}{$\begin{array}{c}\text { Enrolment } \\
2013\end{array}$} & \multirow{2}{*}{$\begin{array}{c}\text { Renewal } \\
2013\end{array}$} & \multicolumn{2}{|c|}{ Enrolment } \\
\hline & & & One year & Both Years \\
\hline 1. Participation in PSNP & $0.223^{* * *}$ & 0.002 & -0.005 & $0.223^{* * *}$ \\
\hline 2. Participation in PSNP + regional fixed effects & $0.300^{* * *}$ & $0.081 * *$ & -0.003 & $0.346^{* * *}$ \\
\hline & $(0.054)$ & $(0.040)$ & $(0.002)$ & $(0.060)$ \\
\hline 3. Participation in PSNP + regional fixed effects, socio-economic status & $0.306^{* *}$ & $0.086^{* *}$ & -0.030 & $0.350 * * *$ \\
\hline & $(0.053)$ & $(0.036)$ & $(0.024)$ & $(0.059)$ \\
\hline 4. Participation in PSNP + regional fixed effects, socio-economic status, demographic traits & $0.317 * * *$ & $0.093^{* *}$ & -0.033 & $0.360^{* * *}$ \\
\hline & $(0.054)$ & $(0.037)$ & $(0.026)$ & $(0.060)$ \\
\hline 5. Participation in PSNP + regional fixed effects, socio-economic status, demographic traits, health status & $0.313^{* * *}$ & $0.097 * * *$ & -0.033 & $0.357 * * *$ \\
\hline & $(0.056)$ & $(0.036)$ & $(0.026)$ & $(0.061)$ \\
\hline $\begin{array}{l}\text { 6. Participation in PSNP + regional fixed effects, socio-economic status, demographic traits, health status, understanding of } \\
\text { health insurance, household member has official position }\end{array}$ & $\begin{array}{l}0.2849 * * * \\
(0.056)\end{array}$ & $\begin{array}{l}0.101 * * * \\
(0.034)\end{array}$ & $\begin{array}{l}-0.033 \\
(0.027)\end{array}$ & $\begin{array}{l}0.334^{* * *} \\
(0.060)\end{array}$ \\
\hline $\begin{array}{l}\text { 7. Participation in PSNP + regional fixed effects, socio-economic status, demographic traits, health status, understanding of } \\
\text { health insurance, household member has official position, access to credit }\end{array}$ & $\begin{array}{l}0.2880 * * * \\
(0.056)\end{array}$ & $\begin{array}{c}0.101 * * * \\
(0.034)\end{array}$ & $\begin{array}{l}-0.035 \\
(0.028)\end{array}$ & $\begin{array}{c}0.341 * * * \\
(0.061)\end{array}$ \\
\hline $\begin{array}{l}\text { 8. Participation in PSNP + regional fixed effects, socio-economic status, demographic traits, health status, understanding of } \\
\text { health insurance, household member has official position, access to credit, supply-side characteristics }\end{array}$ & $\begin{array}{c}0.242^{* * *} \\
(0.058)\end{array}$ & $\begin{array}{l}0.102 * * * \\
(0.037)\end{array}$ & $\begin{array}{l}-0.014 \\
(0.022)\end{array}$ & $\begin{array}{l}0.266^{* * *} \\
(0.061)\end{array}$ \\
\hline $\begin{array}{l}\text { 9. Participation in PSNP + regional fixed effects, socio-economic status, demographic traits, health status, understanding of } \\
\text { health insurance, household member has official position, access to credit, supply-side characteristics, experience with } \\
\text { CBHI }\end{array}$ & . & $\begin{array}{c}0.099 * * * \\
(0.0340)\end{array}$ & & . \\
\hline Observations & 1,147 & 455 & 1147 & 1147 \\
\hline
\end{tabular}


Table 4

Descriptive statistics by PSNP membership status

\begin{tabular}{|c|c|c|c|c|c|c|c|}
\hline \multirow{3}{*}{ Variable } & \multicolumn{4}{|c|}{ PSNP Membership } & \multirow{3}{*}{$\begin{array}{l}\text { Mean } \\
\text { diff. } \\
\text { p-value }\end{array}$} & \multirow{2}{*}{\multicolumn{2}{|c|}{ Total }} \\
\hline & \multicolumn{2}{|c|}{ Member } & \multicolumn{2}{|c|}{ Non-member } & & & \\
\hline & Mean & SD & Mean & SD & & Mean & SD \\
\hline \multicolumn{8}{|l|}{ Socioeconomic status } \\
\hline Poorest consumption quintile & 0.31 & 0.47 & 0.18 & 0.38 & 0.0000 & 0.20 & 0.40 \\
\hline 2nd consumption quintile & 0.19 & 0.39 & 0.20 & 0.40 & 0.6721 & 0.20 & 0.40 \\
\hline 3rd consumption quintile & 0.19 & 0.40 & 0.20 & 0.40 & 0.7699 & 0.20 & 0.40 \\
\hline 4th consumption quintile & 0.19 & 0.40 & 0.20 & 0.40 & 0.8453 & 0.20 & 0.40 \\
\hline Richest consumption quintile & 0.11 & 0.32 & 0.22 & 0.41 & 0.0007 & 0.20 & 0.40 \\
\hline HH head education- No education at all & 0.50 & 0.50 & 0.41 & 0.49 & 0.0234 & 0.43 & 0.49 \\
\hline HH head education- Informal & 0.09 & 0.29 & 0.18 & 0.38 & 0.0022 & 0.16 & 0.37 \\
\hline HH head education- Primary or above & 0.41 & 0.49 & 0.41 & 0.49 & 0.9602 & 0.41 & 0.49 \\
\hline \multicolumn{8}{|l|}{ Demographic traits } \\
\hline Male headed HH & 0.78 & 0.41 & 0.89 & 0.32 & 0.0001 & 0.87 & 0.34 \\
\hline Age of HH head & 48.2 & 13.8 & 47.9 & 13.9 & 0.7696 & 47.9 & 13.9 \\
\hline Household size & 5.67 & 2.22 & 5.94 & 2.24 & 0.1203 & 5.89 & 2.24 \\
\hline Prop. of children aged under 6 & 0.13 & 0.15 & 0.13 & 0.14 & 0.8478 & 0.13 & 0.14 \\
\hline Prop. of male aged 6 to 15 & 0.17 & 0.16 & 0.15 & 0.15 & 0.2738 & 0.15 & 0.15 \\
\hline Prop. of female aged 6 to 15 & 0.15 & 0.15 & 0.15 & 0.14 & 0.7840 & 0.15 & 0.15 \\
\hline Prop. of male aged 16 to 64 & 0.22 & 0.16 & 0.26 & 0.16 & 0.0009 & 0.25 & 0.16 \\
\hline Prop. of female aged 16 to 64 & 0.28 & 0.17 & 0.26 & 0.15 & 0.1275 & 0.26 & 0.15 \\
\hline Prop. of elderly aged above 64 & 0.05 & 0.15 & 0.05 & 0.14 & 0.6163 & 0.05 & 0.14 \\
\hline \multicolumn{8}{|l|}{ Health status } \\
\hline Prop. of household members with poor self-assessed health & 0.11 & 0.21 & 0.19 & 0.32 & 0.0006 & 0.18 & 0.31 \\
\hline Prop. of household members with good self-assessed health & 0.88 & 0.22 & 0.80 & 0.33 & 0.0004 & 0.81 & 0.32 \\
\hline Past illness event - total number of days ill in past 2 months & 7.36 & 16.9 & 6.35 & 14.2 & 0.3779 & 6.52 & 14.7 \\
\hline $\begin{array}{l}\text { Chronic illness }- \text { no. of household members with symptoms } \\
\text { for more than } 30 \text { days }\end{array}$ & 0.29 & 0.89 & 0.16 & 0.65 & 0.0224 & 0.18 & 0.69 \\
\hline \multicolumn{8}{|l|}{ Access to credit } \\
\hline Savings in bank account & 0.10 & 0.30 & 0.13 & 0.34 & 0.2377 & 0.12 & 0.33 \\
\hline Outstanding loan & 0.39 & 0.49 & 0.25 & 0.43 & 0.0001 & 0.28 & 0.44 \\
\hline Member of Iqqub - informal rotating savings/credit group & 0.04 & 0.20 & 0.07 & 0.25 & 0.1419 & 0.06 & 0.24 \\
\hline Member of a formal credit \& saving association & 0.07 & 0.26 & 0.12 & 0.33 & 0.0398 & 0.11 & 0.31 \\
\hline Observations & \multicolumn{2}{|c|}{234} & \multicolumn{2}{|c|}{964} & & \multicolumn{2}{|c|}{1198} \\
\hline
\end{tabular}

Notes: The PSNP refers to membership status of the households in the productive safety net program in 2013 and all household characteristics are according to the 2012 household survey and the 2011 health facility survey. 
Table 5

Probability of PSNP membership - marginal effects after logit (std. error)

\begin{tabular}{|c|c|c|}
\hline \multirow[t]{2}{*}{ VARIABLES } & \multicolumn{2}{|c|}{ Participation in PSNP } \\
\hline & 2013 & 2012 \\
\hline \multicolumn{3}{|l|}{ Socioeconomic status } \\
\hline 2nd consumption quintile (ref: poorest consumption quintile) & $\begin{array}{c}-0.0647 * * * \\
(0.0185)\end{array}$ & $\begin{array}{c}-0.0601 * * * \\
(0.0207)\end{array}$ \\
\hline 3rd consumption quintile & $\begin{array}{l}-0.0586 * * * \\
(0.0194)\end{array}$ & $\begin{array}{l}-0.0754 * * * \\
(0.0206)\end{array}$ \\
\hline 4th consumption quintile & $\begin{array}{c}-0.0666^{* * *} \\
(0.0199)\end{array}$ & $\begin{array}{c}-0.0575^{* *} \\
(0.0232)\end{array}$ \\
\hline Richest consumption quintile & $\begin{array}{c}-0.0980 * * * \\
(0.0192)\end{array}$ & $\begin{array}{l}-0.123^{* * *} \\
(0.0198)\end{array}$ \\
\hline $\mathrm{HH}$ head education- Informal (ref: no education at all) & $\begin{array}{r}-0.0320 \\
(0.0254)\end{array}$ & $\begin{array}{l}-0.0287 \\
(0.0297)\end{array}$ \\
\hline HH head education- Primary or above & $\begin{array}{c}0.0148 \\
(0.0219)\end{array}$ & $\begin{array}{c}0.0137 \\
(0.0226)\end{array}$ \\
\hline \multicolumn{3}{|l|}{ Health status } \\
\hline $\begin{array}{l}\text { Prop. of household members with good SAH (ref: Prop. of } \\
\text { household members with poor SAH) }\end{array}$ & $\begin{array}{c}0.157 * * * \\
(0.0417)\end{array}$ & $\begin{array}{c}0.0772^{* * *} \\
(0.0280)\end{array}$ \\
\hline Past illness event & $\begin{array}{c}0.000404 \\
(0.000574)\end{array}$ & $\begin{array}{l}-0.000433 \\
(0.000715)\end{array}$ \\
\hline Chronic illness & $\begin{array}{l}0.0290^{* *} \\
(0.0118)\end{array}$ & $\begin{array}{l}-0.0295^{*} \\
(0.0165)\end{array}$ \\
\hline \multicolumn{3}{|l|}{ Access to credit } \\
\hline Saving in bank account & $\begin{array}{c}-0.0232 \\
(0.0261)\end{array}$ & $\begin{array}{c}-0.0520 * * \\
(0.0236)\end{array}$ \\
\hline Outstanding loan & $\begin{array}{l}0.0692 * * * \\
(0.0238)\end{array}$ & $\begin{array}{l}0.0827 * * * \\
(0.0251)\end{array}$ \\
\hline Member of Iqqub & $\begin{array}{l}-0.0252 \\
(0.0351)\end{array}$ & $\begin{array}{l}0.0136 \\
(0.0443)\end{array}$ \\
\hline Member of credit and saving association & $\begin{array}{l}-0.0310 \\
(0.0276)\end{array}$ & $\begin{array}{l}-0.0129 \\
(0.0334)\end{array}$ \\
\hline $\begin{array}{l}\text { Observations } \\
\text { Pseudo R-squared } \\
\text { Log pseudo likelihood }\end{array}$ & $\begin{array}{c}1159 \\
0.2011 \\
-420.835\end{array}$ & $\begin{array}{c}1185 \\
0.2796 \\
-422.148\end{array}$ \\
\hline
\end{tabular}

Notes: Outcome variable is one if a household is affiliated to the PSNP in 2013/2012 and zero otherwise. All explanatory variables are at their 2012/2011 values; clustered standard errors in parentheses; *** $\mathrm{p}<0.01$, ** $\mathrm{p}<0.05, * \mathrm{p}<0.1$. The specification also includes a set of demographic characteristics and regional fixed effects. 
Table 6

CBHI experience and design features by PSNP membership status

\begin{tabular}{|c|c|c|c|c|c|c|c|}
\hline \multirow{3}{*}{ Variable } & \multicolumn{4}{|c|}{ PSNP Membership } & \multirow{3}{*}{$\begin{array}{c}\text { Mean } \\
\text { diff. } \\
\text { p-value }\end{array}$} & \multirow{2}{*}{\multicolumn{2}{|c|}{ Total }} \\
\hline & \multicolumn{2}{|c|}{ Member } & \multicolumn{2}{|c|}{ Non-member } & & & \\
\hline & Mean & SD & Mean & SD & & Mean & SD \\
\hline \multicolumn{8}{|l|}{ Affordability of scheme } \\
\hline The timing of premium payment - convenient & 0.70 & 0.46 & 0.82 & 0.38 & 0.0048 & 0.79 & 0.41 \\
\hline CBHI registration fee - affordable & 0.83 & 0.38 & 0.84 & 0.36 & 0.7586 & 0.84 & 0.37 \\
\hline CBHI premium - affordable & 0.76 & 0.43 & 0.77 & 0.42 & 0.9140 & 0.76 & 0.42 \\
\hline Capacity to afford CBHI - Low & 0.21 & 0.41 & 0.19 & 0.39 & 0.5374 & 0.19 & 0.39 \\
\hline Capacity to afford CBHI - Medium & 0.15 & 0.36 & 0.10 & 0.30 & 0.1386 & 0.11 & 0.32 \\
\hline Capacity to afford CBHI - High & 0.64 & 0.48 & 0.71 & 0.45 & 0.1226 & 0.70 & 0.46 \\
\hline \multicolumn{8}{|l|}{ Pressure and fee waiver to join CBHI scheme } \\
\hline Joined the scheme because of pressure - Yes & 0.15 & 0.36 & 0.08 & 0.28 & 0.0322 & 0.10 & 0.30 \\
\hline Joined the scheme without contribution - Yes & 0.03 & 0.16 & 0.03 & 0.18 & 0.7821 & 0.03 & 0.17 \\
\hline \multicolumn{8}{|l|}{ Understanding of health insurance } \\
\hline Only sick people buy CBHI - Appropriate response & 0.77 & 0.42 & 0.69 & 0.46 & 0.0173 & 0.70 & 0.46 \\
\hline $\mathrm{CBHI}$ is same as saving scheme - Appropriate response & 0.73 & 0.45 & 0.72 & 0.45 & 0.7124 & 0.72 & 0.45 \\
\hline CBHI finances health care - Appropriate response & 0.68 & 0.47 & 0.68 & 0.47 & 0.9424 & 0.68 & 0.47 \\
\hline $\begin{array}{l}\text { CBHI premium can be returned if health care not used- } \\
\text { Appropriate response }\end{array}$ & 0.67 & 0.47 & 0.65 & 0.48 & 0.6811 & 0.65 & 0.48 \\
\hline Health insurance understanding - Low $(<=2$ correct) & 0.31 & 0.46 & 0.32 & 0.47 & 0.6333 & 0.32 & 0.47 \\
\hline Health insurance understanding - Medium (3 correct) & 0.23 & 0.42 & 0.22 & 0.42 & 0.7613 & 0.22 & 0.42 \\
\hline Health insurance understanding level - High (4 correct) & 0.46 & 0.50 & 0.45 & 0.50 & 0.8467 & 0.46 & 0.50 \\
\hline \multicolumn{8}{|l|}{ Knowledge of \& participation in CBHI scheme } \\
\hline No of CBHI meetings attended before implementation & 2.92 & 3.00 & 2.49 & 1.60 & 0.0198 & 2.57 & 1.94 \\
\hline Involved in $\mathrm{CBHI}$ management & 0.16 & 0.36 & 0.07 & 0.26 & 0.0002 & 0.09 & 0.28 \\
\hline Official position held & 0.10 & 0.30 & 0.23 & 0.42 & 0.0000 & 0.21 & 0.41 \\
\hline Observations & \multicolumn{2}{|c|}{234} & \multicolumn{2}{|c|}{964} & & \multicolumn{2}{|c|}{1198} \\
\hline
\end{tabular}

Notes: The PSNP refers to membership status of the households in the productive safety net program in 2013 and all household characteristics are according to their value in 2012 households survey. 